\title{
CORRIGENDUM
}

\section{Adolescents' Daily Perception of Internalizing Emotional States by Means of Smartphone-based Ecological Momentary Assessment - CORRIGENDUM}

Teresa Kirchner, Ernesto Magallón-Neri, Manuel S. Ortiz, Irina Planellas, María Forns and Caterina Calderón

doi:10.1017/sjp.2017.70. Published online by Cambridge University Press, 4 December 2017.

In the above mentioned article, an error has been introduced in the 'How to cite this article' box on page 1 of the article.

Kircher, T., Magallón-Neri, E., Ortiz, M. S., Planellas, I., Forns, M., \& Calderón, C. (2017). Adolescents' daily perception of internalizing emotional states by means of smartphone-based ecological momentary assessment. The Spanish Journal of Psychology, 20. e71. Doi:10.1017/ sjp. 2017.70

Should read:

Kirchner, T., Magallón-Neri, E., Ortiz, M. S., Planellas, I., Forns, M., \& Calderón, C. (2017). Adolescents' daily perception of internalizing emotional states by means of smartphone-based ecological momentary assessment. The Spanish Journal of Psychology, 20. e71. Doi:10.1017/ sjp. 2017.70

\section{Reference}

Kirchner T., Magallón-Neri E., Ortiz M. S., Planellas I., Forns M., \& Calderón C. (2017). Adolescents' daily perception of internalizing emotional states by means of smartphone-based ecological momentary assessment. The Spanish Journal of Psychology, 20. e71. Doi:10.1017/ sjp.2017.70 